\title{
Model-based assessment of the safety of community interventions with primaquine in sub-Saharan Africa
}

Stijn W. van Beek ${ }^{1 *}$, Elin M. Svensson 1,2, Alfred B. Tiono ${ }^{3}$, Joseph Okebe ${ }^{4}$, Umberto D’Alessandro $^{5}$, Bronner P. Gonçalves ${ }^{6}$, Teun Bousema ${ }^{7}$, Chris Drakeley ${ }^{6 *}$ and Rob ter Heine ${ }^{1}$

\begin{abstract}
Background: Single low-dose primaquine (SLD-PQ) is recommended in combination with artemisinin-based combination therapy to reduce Plasmodium falciparum transmission in areas threatened by artemisinin resistance or aiming for malaria elimination. SLD-PQ may be beneficial in mass drug administration (MDA) campaigns to prevent malaria transmission but uptake is limited by concerns of hemolysis in glucose-6-phosphate dehydrogenase (G6PD)-deficient individuals. The aim of this study was to improve the evidence on the safety of MDA with SLD-PQ in a sub-Saharan African setting.
\end{abstract}

Methods: A nonlinear mixed-effects model describing the pharmacokinetics and treatment-induced hemolysis of primaquine was developed using data from an adult ( $n=16$, G6PD deficient) and pediatric study $(n=38$, G6PD normal). The relationship between primaquine pharmacokinetics and hemolysis was modeled using an established erythrocyte lifespan model. The safety of MDA with SLD-PQ was explored through Monte Carlo simulations for SLD-PQ at 0.25 or $0.4 \mathrm{mg} / \mathrm{kg}$ using baseline data from a Tanzanian setting with detailed information on hemoglobin concentrations and G6PD status.

Results: The predicted reduction in hemoglobin levels following SLD-PQ was small and returned to pre-treatment levels after 25 days. G6PD deficiency (African A-variant) was associated with a 2.5-fold (95\% Cl 1.2-8.2) larger reduction in hemoglobin levels. In the Tanzanian setting where $43 \%$ of the population had at least mild anemia (hemoglobin $<11-13 \mathrm{~g} / \mathrm{dl}$ depending on age and sex) and $2.73 \%$ had severe anemia (hemoglobin $<7-8 \mathrm{~g} / \mathrm{dl}$ depending on age and sex), an additional $3.7 \%$ and $6.0 \%$ of the population were predicted to develop at least mild anemia and $0.25 \%$ and $0.41 \%$ to develop severe anemia after 0.25 and $0.4 \mathrm{mg} / \mathrm{kg} S L D-P Q$, respectively. Children $<5$ years of age and women $\geq 15$ years of age were found to have a higher chance to have low pre-treatment hemoglobin.

Conclusions: This study supports the feasibility of MDA with SLD-PQ in a sub-Saharan African setting by predicting small and transient reductions in hemoglobin levels. In a setting where a substantial proportion of the population had low hemoglobin concentrations, our simulations suggest treatment with SLD-PQ would result in small increases in the prevalence of anemia which would most likely be transient.

Keywords: Primaquine, Malaria, Plasmodium falciparum, Mass Drug Administration, Modeling, G6PD, Anemia

\footnotetext{
*Correspondence: Stijn.vanBeek@radboudumc.nl; Chris.Drakeley@lshtm.ac.uk ' Department of Pharmacy, Radboud Institute for Health Sciences, Radboud University Medical Center, Nijmegen, The Netherlands ${ }^{6}$ London School of Hygiene \& Tropical Medicine, London, UK

Full list of author information is available at the end of the article
}

\section{Background}

The annual number of malaria cases is estimated at 228 million, most of them in sub-Saharan Africa [1]. Plasmodium falciparum is the main malaria species in this original author(s) and the source, provide a link to the Creative Commons licence, and indicate if changes were made. The images or other third party material in this article are included in the article's Creative Commons licence, unless indicated otherwise in a credit line to the material. If material is not included in the article's Creative Commons licence and your intended use is not permitted by statutory regulation or exceeds the permitted use, you will need to obtain permission directly from the copyright holder. To view a copy of this licence, visit http://creativecommons.org/licenses/by/4.0/. The Creative Commons Public Domain Dedication waiver (http://creativeco mmons.org/publicdomain/zero/1.0/) applies to the data made available in this article, unless otherwise stated in a credit line to the data. 
region. The transmission of malaria depends on the presence of sexual stage parasites, or gametocytes. Primaquine is the only currently available drug targeting mature Plasmodium falciparum gametocytes. To decrease transmission and limit development of artemisinin resistance, a single low dose of primaquine (SLD-PQ) is recommended by the World Health Organization (WHO) in combination with an artemisinin-based combination therapy [1-3]. As artemisinin resistance is emerging in sub-Saharan Africa, strategies that could limit resistance are much needed [4]. However, concerns using SLD-PQ exist because of the risk of hemolysis, especially in individuals with (severe forms of) glucose6-phosphate dehydrogenase (G6PD) deficiency $[2,5,6]$. Primaquine-induced hemolysis may predominantly be driven by cytochrome P450 D6 (CYP2D6)-mediated metabolites [7-9].

The WHO recommends mass drug administration (MDA) for interruption of transmission in areas approaching elimination with good access to treatment and surveillance [1]. MDA consists of treating a defined population in a certain area at approximately the same time with therapeutic doses of an antimalarial. SLD-PQ at $0.25 \mathrm{mg}$ per $\mathrm{kg}$ body weight is recommended for MDA targeting Plasmodium falciparum malaria [10]; this dose is considered safe even for G6PD-deficient individuals, and the WHO recommends it may be administered without testing for G6PD deficiency [2, 11-13]. However, most of the studies that assessed safety have been performed in small populations with relatively high pretreatment hemoglobin levels. Moreover, pragmatic dosing strategies may result in some individuals receiving a higher dose than the recommended $0.25 \mathrm{mg} / \mathrm{kg}$, which may achieve better gametocyte clearance but potentially increase the risk of hemolysis [14-16]. If co-administered with dihydroartemisinin-piperaquine (DP) instead of artemether-lumefantrine (AL), it may even be needed to use a target dose of $0.4 \mathrm{mg} / \mathrm{kg}$ to achieve the same level of gametocyte clearance [16]. This leaves the question whether some populations would still be at risk of clinically relevant hemolysis when SLD-PQ is used at population level. The aim of this study was, therefore, to predict the safety of SLD-PQ when used in MDA campaigns in a sub-Saharan African setting using population pharmacokinetic/pharmacodynamic modeling.

\section{Methods}

\section{Data}

Table 1 shows the characteristics of the participants included in the two studies who provided pharmacokinetic data [11, 12]. The first study was a randomized placebo-controlled trial in children from Balonghin, Burkina Faso [11]. The purpose of the study was to assess
Table 1 Characteristics of the populations included in the analysis

\begin{tabular}{lll}
\hline Characteristic & Pediatric $^{\mathrm{a}}$ & Adult $^{\mathrm{b}}$ \\
\hline Number of patients & 38 & 16 \\
G6PD deficient & No & Yes \\
Males, \% & 42.1 & 100 \\
P. falciparum infected, \% & 100 & 69 \\
Number treated with 0.25 mg/kg pri- & 18 & 10 \\
maquine & & \\
Number treated with 0.4 mg/kg pri- & 20 & 6 \\
maquine & & \\
Age in years, median (range) & $9.5(2-14)$ & $24.5(13-44)$ \\
Weight in kg, median (range) & $23.3(12.1-43.5)$ & $55.4(29.9-76.4)$ \\
Baseline Hb in g/dl, median (range) & $11.7(9.3-13.8)$ & $13.1(12-15.4)$ \\
Number of pharmacokinetic samples & 228 & 97 \\
Pharmacokinetic data BLQ, \% & 14.2 & 25.2 \\
Number of Hb samples & 226 & 199 \\
CYP2D6 AS distribution, $n$ (\%) & & \\
0 & $1(2.63)$ & $0(0)$ \\
0.5 & $4(10.5)$ & $4(25)$ \\
1 & $6(15.8)$ & $1(6.25)$ \\
1.5 & $13(34.2)$ & $7(43.75)$ \\
2 & $7(18.4)$ & $3(18.75)$ \\
3 & $3(7.89)$ & $0(0)$ \\
Missing & $4(10.5)$ & $1(6.25)$ \\
\hline ariging & &
\end{tabular}

${ }^{a}$ Original data from Goncalves et al [11]. ${ }^{\mathrm{b}}$ Original data from Bastiaens et al. [12]. AS: activity score; BLQ: below limit of quantification; CYP2D6: cytochrome P450 D6; Hb: hemoglobin

the effect of SLD-PQ $(0.25$ and $0.4 \mathrm{mg} / \mathrm{kg})$ on the transmission of malaria. The study included Plasmodium falciparum-infected children aged 2-15 years without any malaria symptoms and normal G6PD activity. The children were treated with $\mathrm{AL}$ alone, $\mathrm{AL}$ and $0.25 \mathrm{mg} / \mathrm{kg}$ primaquine, or $\mathrm{AL}$ and $0.40 \mathrm{mg} / \mathrm{kg}$ primaquine. AL was given twice daily for 3 days, and primaquine or placebo was administered with the fifth dose of AL. A subset of 40 children was included in a pharmacokinetic sub-study. One blood sample was taken pre-dose, four in the first $12 \mathrm{~h}$ and two between 24 and $72 \mathrm{~h}$ after dosing. Hemoglobin concentrations were quantified using a HemoCue photometer (HemoCue AB, Angelholm, Sweden) on days 0 (pre-dosing), 2, 3, 7, 10 and 14. Two of the 40 children were excluded because of undeterminable primaquine concentrations. In total, 228 pharmacokinetic samples and 226 hemoglobin samples from 38 children were included in the analysis.

The second study was an open-label, randomized, dose-escalation trial in G6PD-deficient (African A- variant) adult males from Burkina Faso and The Gambia [12]. The purpose of the study was to assess the safety of SLD-PQ $(0.25 \mathrm{mg} / \mathrm{kg}$ and $0.4 \mathrm{mg} / \mathrm{kg})$ in G6PD-deficient 
African males. All individuals from Burkina Faso and some from The Gambia were Plasmodium falciparum malaria infected and asymptomatic. The participants were treated either with AL (Burkina Faso) or DP (The Gambia) alone or in combination with primaquine. Six pharmacokinetic samples were taken up to $72 \mathrm{~h}$ post dose from 16 participants. Randomized sampling times were allocated so that there were four samples on day 0 (day of dosing) and one each on days 1 and 2 per individual. Hemoglobin concentrations were assessed on day 0 (predosing), twice daily on days 1, 2 and 3, and once daily on days 4, 5, 7, 10, 14 and 28 using self-calibrating HemoCue 201+ photometers (HemoCue AB, Angelholm, Sweden). From this second study, 97 pharmacokinetic samples and 199 hemoglobin samples were included in the analysis.

\section{Quantification of primaquine and genotyping of G6PD and CYP2D6}

Primaquine plasma levels were quantified using liquid chromatography-mass spectrometry at two different laboratories as previously described with lower limits of quantification of $4 \mathrm{ng} / \mathrm{ml}$ and $1.14 \mathrm{ng} / \mathrm{ml}$ for the first and second study, respectively [12, 17, 18]. For the first study, G6PD status was determined using the BinaxNow rapid diagnostic test (Alere Inc., Waltham, MA, USA) as described in the original publication [11]. For the second study, G6PD status was determined using Beutler's fluorescence spot test (R\&D Diagnostics, Greece) [12]. For both studies, CYP2D6 genotype was determined with Quantstudio 12K Flex OpenArray with TaqMan assays (Thermo Fisher Scientific, Waltham, MA, USA) [12, 18].

\section{Pharmacokinetic/pharmacodynamic modeling}

The analysis of the pharmacokinetic data and the relationship with hemoglobin concentrations over time was performed by means of nonlinear mixed-effects modeling. Model structure and estimates of previous work on the pediatric dataset were used as a starting point for the pharmacokinetic analysis [18]. Three transit compartments described the gradual absorption of primaquine. The model incorporated a well-stirred liver model [19]. Liver volume was calculated from total body weight and height [20]. A liver plasma flow of $49.5 \mathrm{l} / \mathrm{h}$ was assumed, derived from an adult total blood flow of $90 \mathrm{l} / \mathrm{h}$ and a plasma fraction of $55 \%$ in whole blood (hematocrit level $45 \%)$. Allometric scaling to a total body weight of $70 \mathrm{~kg}$ for volume, clearance and liver plasma flow parameters was included to account for differences in weight, with exponents of respectively 1 and 0.75 for volume and clearance parameters [21]. The bioavailability of primaquine was assumed to be $100 \%$, and all estimated parameters are apparent oral pharmacokinetic parameters. Primaquine pharmacokinetic data below the limit of quantification were handled using the M3 method as described by Beal et al. [22].

CYP2D6 activity score (AS), a quantitative measure of phenotype, was inferred from the CYP2D6 genotype [23, 24]. The AS value for an individual can be, going from no to high activity, $0,0.5,1,1.5,2$ or 3 . The CYP2D6 AS was included as a covariate on the CYP2D6-mediated clearance. Quantification of the CYP2D6-mediated metabolites is difficult, and no usable pharmacokinetic data were available [21]. The same relationship between AS and CYP2D6-mediated clearance as in the model built on the pediatric data was included in the current model as alternative relationships could not be explored because of the lack of data on these metabolites [18]. The individual CYP2D6-mediated clearance was calculated as follows:

$$
\mathrm{CL}_{\mathrm{CYP2D6} \text {,individual }}=\mathrm{CL}_{\mathrm{CYP2D} \text {, population }} \cdot \mathrm{AS} \cdot\left(\frac{\mathrm{WT}}{70}\right)^{0.75}
$$

where the $\mathrm{CL}_{\mathrm{CYP} 2 \mathrm{D} 6 \text {,population }}$ is the estimated population CYP2D6-mediated clearance, AS is the CYP2D6 activity score, and WT is the total body weight. Missing CYP2D6 AS (11\% in the pediatric study and $7 \%$ in the adult study) was imputed with the most prevalent score of 1.5. As no pharmacokinetic data on the CYP2D6-mediated metabolites were used, it was decided a priori that a single compartment with volume and clearance parameters fixed to 1 would describe the pharmacokinetics of the CYP2D6-mediated metabolites. The metabolite compartment describes a virtual CYP2D6-dependent metabolite concentration, expressed as arbitrary unit per milliliter. Carboxyprimaquine and other metabolites of primaquine were not described by the model.

The pharmacodynamic model was developed following the pharmacokinetic model, using individual pharmacokinetic parameter estimates as input. The relationship between primaquine metabolite concentrations and hemolysis was modeled using an established erythrocyte lifespan model [25]. The erythrocyte lifespan model, shown in the lower half of Fig. 1, included four transit compartments and a concentration-slope effect describing the elimination of erythrocytes following primaquine-induced hemolysis caused by the CYP2D6mediated metabolites. As hemoglobin is directly correlated with erythrocyte count, all lifespan compartments together make up the total hemoglobin value for an individual. The effect of G6PD deficiency on the primaquineinduced hemolysis was described by estimating a scaling factor on the concentration-slope effect. The primaquineinduced hemolysis (elimination of erythrocytes $-K_{\text {eryth- }}$ rocyte elimination) was calculated as follows:

$$
K_{\text {erythrocyte elimination }}=C_{\mathrm{CYP2D} 6 \text { metabolites }} \cdot \text { Slope } \cdot F_{\mathrm{G} 6 \mathrm{PDd}}
$$




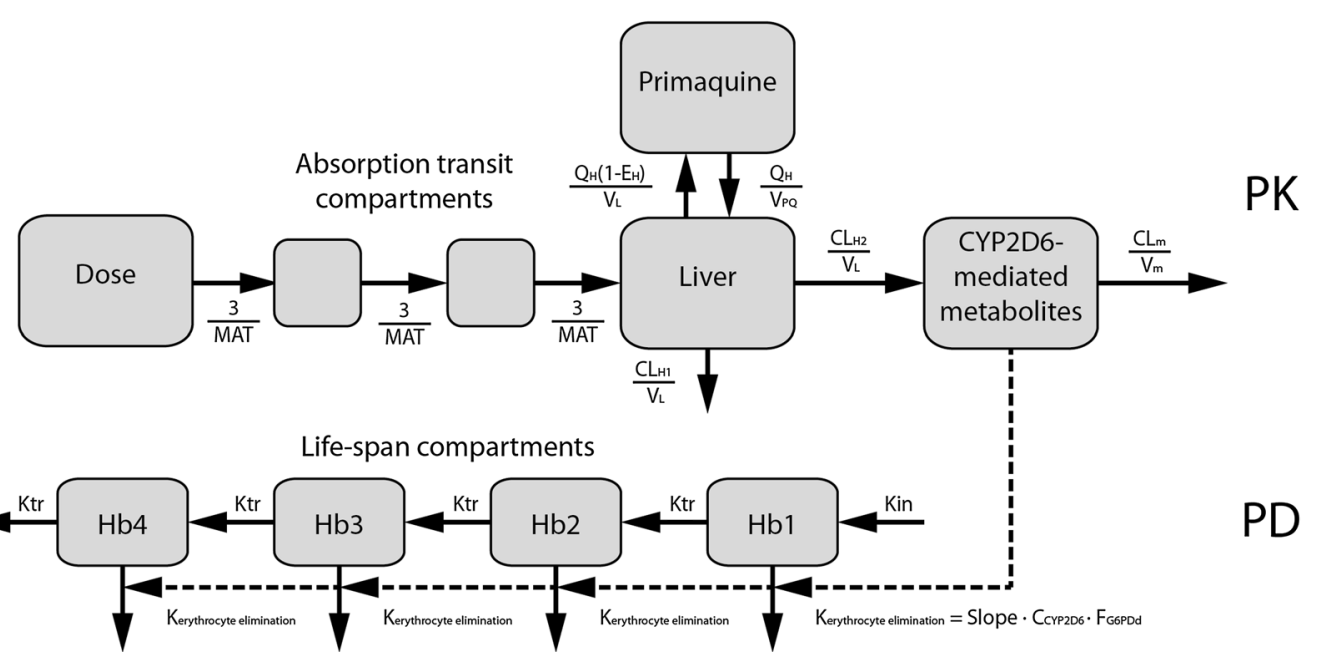

Fig. 1 Schematic of the final pharmacokinetic/pharmacodynamic model. The pharmacokinetic model is on the upper half of the figure and the pharmacodynamic model on the lower half. $C_{\mathrm{CYP} 2 \mathrm{D} 6}$ : concentration in the CYP2D6-mediated metabolite compartment; $\mathrm{CL}_{\mathrm{H} 1}$ : hepatic clearance out of the system; $\mathrm{CL}_{\mathrm{H} 2}$ : CYP2D6-mediated hepatic clearance; $\mathrm{CL}_{m}$ : clearance of the metabolite; CYP2D6: cytochrome P450 D6; $E_{\mathrm{H}}$ : hepatic extraction ratio; $F_{G 6 P D d}$ factor by which the primaquine-induced elimination of erythrocytes is increased in G6PD-deficient individuals; Hb: hemoglobin; Kin:

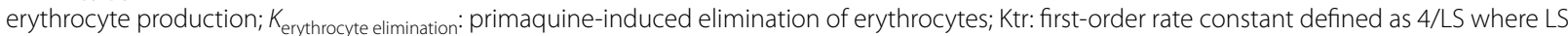
is the erythrocyte lifespan in hours; MAT: mean absorption time; PD: pharmacodynamic; PK: pharmacokinetic; Slope: concentration-slope effect of primaquine-induced elimination of erythrocytes; $V_{L}$ : liver volume; $V_{m}$ : volume of the metabolite compartment; $V_{P Q}$ : volume of the primaquine compartment

where $C_{\text {CYP2D6 metabolites }}$ is the concentration in the CYP2D6-mediated metabolite compartment, Slope is the concentration-slope effect of primaquine-induced elimination of erythrocytes, and $F_{\mathrm{G} 6 \mathrm{PDd}}$ is the factor by which the primaquine-induced elimination of erythrocytes is increased in G6PD-deficient individuals.

Inter-individual variability in the pharmacokinetic and pharmacodynamic parameters was assumed to be lognormally distributed. Residual variability in primaquine pharmacokinetics was implemented using a proportional error model in addition to an additive residual error which was fixed to $50 \%$ of the largest of the two lower limit of quantification values, in line with the M3 method by Beal [22]. For the pharmacodynamic model, additive, proportional and combined models were tested to describe the residual variability. The relative standard errors of the pharmacokinetic and pharmacodynamic parameters were derived from a non-parametric bootstrap with 1000 samples.

\section{Mass drug administration simulations}

The developed model was used to explore the safety of MDA with SLD-PQ in a sub-Saharan African setting through Monte Carlo simulations. For this, we selected a large cross-sectional Tanzanian dataset that included data on age, sex, weight, hemoglobin level $(\mathrm{g} / \mathrm{dl})$ and G6PD status to create a simulation dataset [26, 27]. G6PD deficiency in this population was defined by having the hemizygous or homozygous G202A/A376G genotype, characterizing the G6PD A- variant. Children $<6$ months old were removed from the dataset since we assumed they would not be included in MDA as primaquine is contraindicated for children $<6$ months old and pregnant women [10]. The total number of individuals was 7672 after exclusion of children $<6$ months old and individuals with missing data (568 individuals were removed). Each individual was included four times in the simulation dataset to include more combinations of CYP2D6 status and to assess the effect of inter-individual variability better. CYP2D6 AS was randomly assigned to the sampled individuals according to distributions described in the literature, resulting in probabilities of $0.026,0.101,0.256$, $0.386,0.209$ and 0.022 for an AS of $0,0.5,1,1.5,2$ and 3, respectively $[28,29]$.

Hemoglobin nadir was simulated for a single dose of $0.25 \mathrm{mg} / \mathrm{kg}$ or $0.4 \mathrm{mg} / \mathrm{kg}$ primaquine. We simulated doses assuming that the smallest available tablet size of primaquine is $2.5 \mathrm{mg}$ and that it can be split in two (administered doses are rounded to $1.25 \mathrm{mg}$ increments). The predicted prevalence of different severity classes of anemia at the nadir was assessed as a measure of safety. The severity classes of anemia consisted of mild, moderate and severe anemia and their definitions were adapted from the WHO [30]. Depending on age, sex and 
pregnancy status, the WHO definitions described individuals with hemoglobin levels $<11-13 \mathrm{~g} / \mathrm{dl}$ as mildly anemic, individuals with hemoglobin levels $<7-11 \mathrm{~g} / \mathrm{dl}$ as moderately anemic and individuals with hemoglobin levels $<7-8 \mathrm{~g} / \mathrm{dl}$ as severely anemic. The complete definitions by age, sex and pregnancy status can be found in the supplementary materials (Additional file 1: Table S1).

We also explored whether the incidence of severe anemia could be limited by excluding individuals with pre-treatment hemoglobin levels below a certain threshold from dosing. Based on the hemoglobin distribution within the simulation dataset, we assessed scenarios where individuals with hemoglobin levels $<7,7.5$ and $8 \mathrm{~g} / \mathrm{dl}$ were not treated with primaquine.

\section{Software, parameter estimation and model selection}

$\mathrm{R}$ version 3.4.3 was used for data management, statistics and plotting [31]. Model development was performed using the nonlinear mixed-effects modeling program NONMEM version 7.4 with Pirana as an interface [32, 33]. PsN version 4.7 was used as an aid for advanced functionalities [33]. The Xpose4 $\mathrm{R}$ package version 4.6.1 was used for graphical visualization of the visual predictive checks (VPCs) [33]. The VPCs were performed using 1000 simulations and were prediction and variability corrected [34].

In NONMEM, the Laplacian method with interaction was used for estimation of the pharmacokinetic parameters [35]. For estimation of the pharmacodynamic parameters, the first-order conditional estimation method with interaction was used. Goodness-of-fit plots together with differences in objective function value were used to compare performances between different models. A change in objective function value of $>3.84$ between two nested models was considered statistically significant $(p<0.05)$ for 1 degree of freedom.

\section{Results}

\section{Pharmacokinetic modeling}

Figure 1 shows the model schematic of both the pharmacokinetic and pharmacodynamic models, with the pharmacokinetic model shown in the upper half. The pharmacokinetic model for primaquine in children was successfully extended to adults by means of allometric scaling of the pharmacokinetics on body weight and reestimation of the parameters. The estimated pharmacokinetic parameters and their uncertainty are shown in Table 2. Inter-individual variability was included on the central volume of primaquine, mean absorption time and clearance. Both the CYP2D6-mediated hepatic clearance and hepatic clearance out of the system share the same inter-individual variability. The VPC, goodness-of-fit plots and model code are included within the
Table 2 Final pharmacokinetic and pharmacodynamic model parameters

\begin{tabular}{|c|c|c|}
\hline Parameter & Estimate & $\mathrm{RSE}^{+}, \mathrm{CV} \%$ \\
\hline$V_{\mathrm{PQ}^{\prime}} \mathrm{I}(70 \mathrm{~kg})$ & 130 & 6.05 \\
\hline $\mathrm{CL}_{\mathrm{H} 1}, \mathrm{l} / \mathrm{h}(70 \mathrm{~kg})$ & 25.1 & 8.78 \\
\hline $\mathrm{CL}_{\mathrm{H} 2}, \mathrm{l} / \mathrm{h}(70 \mathrm{~kg})$ & 5.6 & 29.6 \\
\hline MAT, h & 0.915 & 11.2 \\
\hline IIV CL \#, CV\% & 46 & 30.6 \\
\hline$I V V_{P^{\prime}} C V \%$ & 44 & 26.5 \\
\hline IIV MAT, CV\% & 55 & 28.8 \\
\hline Proportional error, \% & 25.3 & 20.0 \\
\hline Additive error, $\mathrm{ng} / \mathrm{ml}^{a}$ & 2 & - \\
\hline Lifespan, $\mathrm{h}$ & 276 & 50 \\
\hline Slope, $C_{\text {CYP2D }}{ }^{-1} \cdot h^{-1}$ & 0.0012 & 49 \\
\hline$F_{\mathrm{G} 6 \mathrm{PDd}}$ & 2.46 & 103 \\
\hline Proportional error Hb, V\% & 6.95 & 4 \\
\hline
\end{tabular}

$\mathrm{C}_{\text {CYP2D }}$ : concentration in the compartment for CYP2D6-mediated metabolites; $\mathrm{CL}_{\mathrm{H} 1}$ : hepatic clearance out of the system; CLH2: CYP2D6-mediated hepatic clearance; $\mathrm{CV}$ : coefficient of variation; $F_{\mathrm{GGPDd}}$ : factor by which the primaquineinduced elimination of erythrocytes is increased in G6PD-deficient individuals; IIV: inter-individual variability; MAT: mean absorption time; RSE: relative standard error; Slope: concentration-slope effect of primaquine-induced elimination of erythrocytes; $V_{\mathrm{PQ}}$ : volume of distribution for primaquine

${ }^{+}$As derived from a non-parametric bootstrap with 1000 samples

\# Both $\mathrm{CL}_{\mathrm{H} 1}$ and $\mathrm{CL}_{\mathrm{H} 2}$ share the same inter-individual variability

${ }^{a}$ Parameter was fixed during parameter estimation

supplemental information (Additional file 2: Figure S1, Additional file 3: Figure S2 and Additional file 5: Model code).

\section{Pharmacodynamic modeling}

The erythrocyte lifespan model schematic is shown in the lower half of Fig. 1. One concentration-slope effect describing the primaquine-induced elimination of erythrocytes was estimated for all four lifespan compartments, as we did not have data on erythrocyte populations with different ages. A lifespan of 276 h (95\% CI 119-654 h) was estimated for both the G6PD-normal and -deficient individuals; separate lifespans for G6PD-normal and -deficient individuals could not be estimated reliably. The effect of G6PD deficiency on the primaquine-induced elimination of erythrocytes was estimated at a 2.46 -fold increase (95\% CI 1.16-8.17-fold). A proportional error model was most appropriate to describe the residual error in the pharmacodynamic model. The pharmacodynamic parameters and their uncertainty are shown in Table 2. The VPC, goodness-of-fit plots and model code are included within the supplemental materials (Additional file 2: Figure S1, Additional file 4: Figure S3 and Additional file 5: Model code).

The predicted reduction in hemoglobin levels for a typical individual (weight $70 \mathrm{~kg}$, length $170 \mathrm{~cm}$, AS 1.5) with 


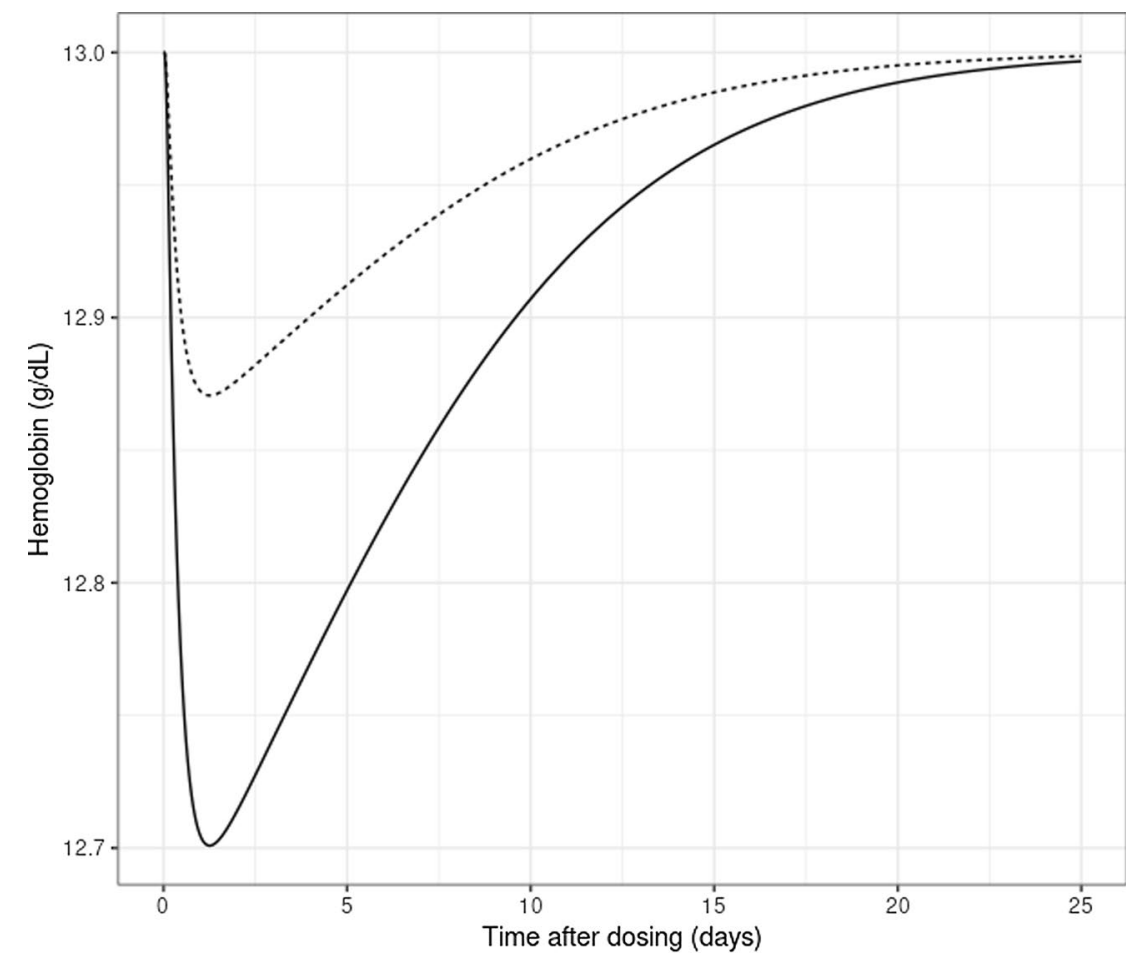

G6PD deficiency

- deficient

.... normal

Fig. 2 Predicted reduction in hemoglobin levels after a single dose of $0.25 \mathrm{mg} / \mathrm{kg}$ primaquine for a typical G6PD-normal and -deficient individual. A typical individual was assumed to have a weight of $70 \mathrm{~kg}$, length of $170 \mathrm{~cm}$, CYP2D6 activity score of 1.5 and pre-treatment hemoglobin of $13 \mathrm{~g} / \mathrm{dl}$

a baseline hemoglobin concentration of $13 \mathrm{~g} / \mathrm{dl}$, with and without G6PD deficiency following a single $0.25 \mathrm{mg} / \mathrm{kg}$ dose, is shown in Fig. 2. For a typical G6PD normal individual, the reduction in hemoglobin from baseline to the nadir is approximately $0.13 \mathrm{~g} / \mathrm{dl}$. For a typical G6PD-deficient individual, this reduction is $0.30 \mathrm{~g} / \mathrm{dl}$. It is predicted to take about 25 days for the hemoglobin concentration to return completely to pre-treatment values.

\section{Mass drug administration simulations}

The median (range) of hemoglobin was 12.1 (2.0-18.8) g/ $\mathrm{dl}$ and prevalence of G6PD deficiency was $5.51 \%$ in the simulation population. Following the linear kinetics of primaquine, the expected maximum concentration and total exposure following $0.4 \mathrm{mg} / \mathrm{kg}$ primaquine are $60 \%$ higher compared to $0.25 \mathrm{mg} / \mathrm{kg}$ primaquine. Table 3 shows the predicted median reduction in hemoglobin levels at the nadir after $0.25 \mathrm{mg} / \mathrm{kg}$ and $0.4 \mathrm{mg} / \mathrm{kg}$ primaquine for the whole population and by G6PD status. A table showing the predicted median reduction in hemoglobin levels by CYP2D6 AS group is included in the supplemental materials (Additional file 6: Table S2).

Table 4 shows the prevalence and grade of anemia after taking $0.25 \mathrm{mg} / \mathrm{kg}$ and $0.4 \mathrm{mg} / \mathrm{kg}$ primaquine. The prevalence of anemia without any intervention was already high $(43.0 \%)$ in this population and even higher (49.6\%)
Table 3 Predicted median reduction in hemoglobin after 0.25 and $0.4 \mathrm{mg} / \mathrm{kg}$ primaquine

\begin{tabular}{llll}
\hline Population & $\begin{array}{l}\text { Primaquine } \\
\text { dose, } \mathrm{mg} / \mathrm{kg}\end{array}$ & $\begin{array}{l}\text { Median } \\
\text { reduction in } \\
\mathrm{Hb}, \mathrm{g} / \mathrm{dl}\end{array}$ & $\begin{array}{l}90 \% \text { prediction interval } \\
\text { of reduction in } \mathrm{Hb}, \mathrm{g} / \mathrm{dl}^{\mathrm{a}}\end{array}$ \\
\hline All & 0.25 & 0.16 & $0.054-0.32$ \\
G6PD normal & 0.4 & 0.26 & $0.088-0.51$ \\
& 0.25 & 0.16 & $0.053-0.28$ \\
G6PD deficient & 0.40 & 0.25 & $0.086-0.45$ \\
& 0.25 & 0.35 & $0.12-0.65$ \\
& 0.4 & 0.56 & $0.21-1.0$ \\
\hline
\end{tabular}

${ }^{a}$ Prediction interval resulting from inter-individual variability

for the G6PD-deficient individuals. After SLD-PQ of $0.25 \mathrm{mg} / \mathrm{kg}$, an additional $3.7 \%$ of the general population was predicted to develop anemia (8.6\% relative increase from pre-treatment prevalence) and an additional $0.25 \%$ to develop severe anemia specifically $(9.2 \%$ relative increase from pre-treatment prevalence). Following a dose of $0.4 \mathrm{mg} / \mathrm{kg}$ primaquine, an additional $6.0 \%$ of the general population was predicted to develop anemia (14\% relative increase from pre-treatment prevalence) and an additional $0.41 \%$ to develop severe anemia (15\% relative increase from pre-treatment prevalence). 
Table 4 Predicted prevalence of anemia and its severity after 0.25 and $0.4 \mathrm{mg} / \mathrm{kg}$ primaquine

\begin{tabular}{|c|c|c|c|c|c|c|}
\hline Population & $\begin{array}{l}\text { Dosing } \\
\text { regimen, mg/ } \\
\text { kg }\end{array}$ & $\begin{array}{l}\text { No anemia } \\
(\mathrm{Hb}>11-13 \mathrm{~g} / \\
\mathrm{dl}), \%\end{array}$ & $\begin{array}{l}\text { All anemia grades } \\
(\mathrm{Hb}<11-13 \mathrm{~g} / \mathrm{dl}), \%\end{array}$ & $\begin{array}{l}\text { Mild anemia (Hb 7-11 } \\
\text { to } 11-13 \mathrm{~g} / \mathrm{dl}), \%\end{array}$ & $\begin{array}{l}\text { Moderate anemia (Hb } \\
7-8 \text { to } 7-11 \mathrm{~g} / \mathrm{dl}), \%\end{array}$ & $\begin{array}{l}\text { Severe anemia } \\
(\mathrm{Hb}<7-8 \mathrm{~g} / \\
\mathrm{dl}), \%\end{array}$ \\
\hline \multirow[t]{3}{*}{ All } & 0 & 57.0 & 43.0 & 18.3 & 22.0 & 2.73 \\
\hline & 0.25 & 53.3 & 46.7 & 19.6 & 24.1 & 2.98 \\
\hline & 0.40 & 51.0 & 49.0 & 20.1 & 25.7 & 3.14 \\
\hline \multirow[t]{3}{*}{ G6PD normal } & 0 & 57.4 & 42.6 & 18.2 & 21.7 & 2.73 \\
\hline & 0.25 & 54.1 & 45.9 & 19.3 & 23.7 & 2.95 \\
\hline & 0.40 & 52.0 & 48.0 & 19.8 & 25.1 & 3.09 \\
\hline \multirow[t]{3}{*}{ G6PD deficient } & 0 & 50.4 & 49.6 & 19.8 & 27.1 & 2.72 \\
\hline & 0.25 & 40.5 & 59.5 & 24.2 & 31.9 & 3.43 \\
\hline & 0.40 & 34.8 & 65.2 & 25.2 & 36.1 & 3.96 \\
\hline
\end{tabular}

The definitions for anemia severity are dependent on age, sex and pregnancy status, and the complete definitions can be found in Additional file 1: Table S1

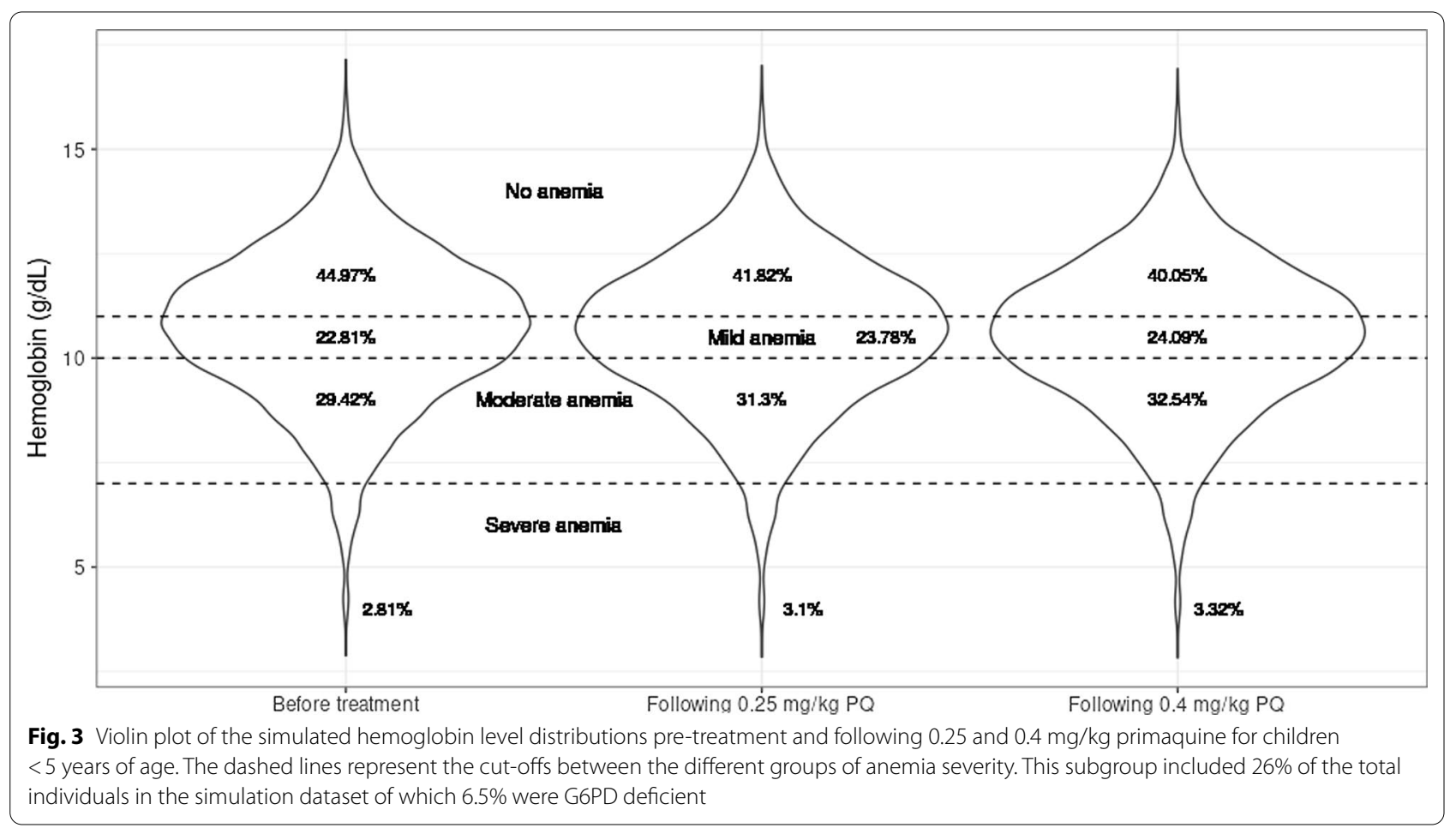

The simulated hemoglobin distribution before treatment and following 0.25 and $0.4 \mathrm{mg} / \mathrm{kg}$ primaquine for children $<5$ years of age is depicted in Fig. 3 . The hemoglobin distributions for the other subgroups used in the anemia definition of the WHO are shown in the supplementary information (Additional file 7: Figure S4). Changes in the distribution of hemoglobin levels after SLD-PQ are minimal. Children $<5$ years of age and women $\geq 15$ years of age have a relatively high proportion of individuals near to and below the cut-off defining severe anemia both before and after treatment.
Excluding individuals with a pre-treatment hemoglobin value $<7,7.5$ or $8 \mathrm{~g} / \mathrm{dl}$ translates into excluding $1.67 \%, 2.35 \%$ and $3.35 \%$ of the population, respectively (Additional file 8: Figure S5). Depending on the threshold, $41-48 \%$ of the excluded individuals are $<5$ years of age compared to $26 \%$ in the general population. Table 5 shows the predicted prevalence of severe anemia after dosing with $0.25 \mathrm{mg} / \mathrm{kg}$ or $0.4 \mathrm{mg} / \mathrm{kg}$ primaquine by exclusion according to different pre-treatment hemoglobin values. For a primaquine dose of $0.25 \mathrm{mg} / \mathrm{kg}$, the proportion of individuals transitioning from moderate 
Table 5 Predicted prevalence of severe anemia after 0.25 or $0.4 \mathrm{mg} / \mathrm{kg}$ primaquine per dosing scenario based on pretreatment hemoglobin level

\begin{tabular}{lll}
\hline Dosing scenario & Dosing regimen, $\mathrm{mg} / \mathrm{kg}$ & $\begin{array}{l}\text { Severe } \\
\text { anemia, } \\
\%\end{array}$ \\
\hline - & 0 & 2.73 \\
Dosing all & 0.25 & 2.98 \\
Dosing $\mathrm{Hb}>7.0 \mathrm{~g} / \mathrm{dl}$ & 0.40 & 3.14 \\
& 0.25 & 2.95 \\
Dosing $\mathrm{Hb}>7.5 \mathrm{~g} / \mathrm{dl}$ & 0.40 & 3.10 \\
& 0.25 & 2.91 \\
Dosing $\mathrm{Hb}>8.0 \mathrm{~g} / \mathrm{dl}$ & 0.40 & 3.03 \\
& 0.25 & 2.86 \\
& 0.40 & 2.97 \\
\hline
\end{tabular}

to severe anemia decreased by $12 \%, 28 \%$ and $48 \%$ when excluding by pre-treatment hemoglobin $<7,7.5$ and $8 \mathrm{~g} /$ $\mathrm{dl}$, respectively (i.e. from 0.25 to $0.13 \%$ of the total population for the $8 \mathrm{~g} / \mathrm{dl}$ threshold). For $0.4 \mathrm{mg} / \mathrm{kg}$ primaquine, this proportion decreased by $10 \%, 22 \%$ and $41 \%$, respectively. After administering $0.4 \mathrm{mg} / \mathrm{kg}$ primaquine excluding individuals with pre-treatment hemoglobin $<8 \mathrm{~g} / \mathrm{dl}$, the prevalence of severe anemia was similar to that after treating everybody with $0.25 \mathrm{mg} / \mathrm{kg}$ primaquine.

\section{Discussion}

Concerns about primaquine safety related to hemolysis have been an obstacle to its wide implementation as the risk is at the individual level while the benefit is only gained at the population level. Contemporary safety studies provide limited information at the population level as they are typically based on selected individuals with relatively high pre-treatment hemoglobin. The present analysis describes an assessment of the relationship between primaquine concentrations and primaquine-induced hemolysis in a semi-mechanistic model with the aim of exploring the safety of an MDA campaign with SLD-PQ in a sub-Saharan African setting. The analysis shows that, post treatment, hemoglobin levels would drop in a minority of individuals to levels below the pre-defined threshold defining (severe) anemia but that this effect is transient. G6PD-deficient individuals were found to be more at risk because of the increased hemolytic effect of primaquine.

The estimated pharmacokinetic parameters were similar between our model and the model built on the pediatric data [18]. The erythrocyte lifespan was estimated at $276 \mathrm{~h}$, or 11.5 days, which is short compared to what is expected in healthy individuals (70-140 days) [36]. However, considering the facts that malaria infection itself drastically reduces erythrocyte lifespan (16-84 days) and that in individuals taking oxidative medication, like primaquine, the lifespan may even be shortened to 2.5-5 days, we consider our findings in line with the literature [37, 38]. Although one may argue that our population predictions for safety in a healthy population may not necessarily be representative as they are based on estimates from mostly malaria-infected patients of which many were G6PD deficient, we consider our predictions a "worst case scenario."

The MDA simulations showed an increase in the prevalence of anemia (hemoglobin $<11-13 \mathrm{~g} / \mathrm{dl}$ ) after a single dose of both $0.25 \mathrm{mg} / \mathrm{kg}$ and $0.4 \mathrm{mg} / \mathrm{kg}$ primaquine of $3.7 \%$ (8.6\% relative increase) and $6.0 \%$ (14\% relative increase), respectively. The increase in the prevalence of anemia was determined at nadir hemoglobin levels following primaquine treatment and was shown to be transient. After reaching the nadir following primaquine administration, the hemoglobin levels quickly recovered to return to baseline again after 25 days such that the reported increases in prevalence of anemia are present for a limited time $[12,39,40]$. The time to hemoglobin recovery was predicted to be independent of G6PD status or hemoglobin levels. The rapid recovery of hemoglobin levels also suggests that consecutive rounds of MDA with at least 1 month in between, as typically implemented $[41,42]$, would be unlikely to affect the prevalence of anemia.

Severe anemia is of most concern clinically, and whilst the relative increase in the prevalence of severe anemia was similar to that of any anemia grade in our Tanzanian setting, the absolute increase was much lower $(0.25 \%$ vs $3.7 \%$ ). This suggests that post-SLD-PQ hemoglobin levels in a small but non-negligible number of individuals might drop below our severe anemia threshold of hemoglobin $<7-8 \mathrm{~g} / \mathrm{dl}$. Again, our predictions suggested this drop would be transient. Acknowledging that individuals with low hemoglobin are at higher risk of developing severe anemia, we investigated the exclusions of individuals with hemoglobin levels below specific thresholds. Children $<5$ years of age and women $\geq 15$ years of age were most likely to have low hemoglobin levels in our simulations and were most at risk to develop severe anemia. As expected, we predicted that the prevalence of individuals with severe anemia is reduced by not treating individuals with low pre-treatment hemoglobin levels $(<7,<7.5$ or $<8 \mathrm{~g} / \mathrm{dl}$ ) although measuring hemoglobin on a large scale may be logistically challenging. Similarly, we predicted that by excluding individuals with hemoglobin values $<8 \mathrm{~g} / \mathrm{dl}, 0.4 \mathrm{mg} / \mathrm{kg}$ primaquine can be used instead of $0.25 \mathrm{mg} / \mathrm{kg}$ without increasing the prevalence of severe anemia. Higher doses of SLD-PQ may be useful in the 
absence of specific low-dose or pediatric formulations of the drug.

It is important to acknowledge that we did not account for females who are heterozygous for G6PD deficiency genes as we did not have the data to do so. Heterozygous females have been described to present with a wide range of G6PD activity. In our analysis we decided to include the heterozygous females in the G6PD normal group as the majority will have a G6PD activity which is closer to normal than deficient activity [43, 44]. We performed a sensitivity analysis by simulating MDA in which heterozygous females were included in the G6PD-deficient group. In this simulation, $17.2 \%$ of the total population was defined to be G6PD deficient instead of $5.5 \%$ in the main analysis. The impact on the prevalence of anemia following SLD-PQ is generally negligible, e.g. the prevalence of severe anemia following $0.25 \mathrm{mg} / \mathrm{kg}$ primaquine increases from $2.98 \%$ to $3.02 \%$. The full results of the sensitivity analysis can be found in the supplementary materials (Additional file 9: Table S3).

The data used to develop the model did not include children $<2$ years of age and our model does not include any enzymatic maturation factors on either the pharmacokinetics or pharmacodynamics. As MDA is recommended to include children from the age of 6 months, the uncertainty in the extrapolation from our model to these younger children should be carefully considered. However, maturation of CYP2D6-dependent metabolism is not thought to play a role at this age [45], and recent findings support the safety of primaquine in young children [46]. A further limitation is that this study included only individuals who were G6PD normal or G6PD deficient with the African A- variant, the dominant variant in sub-Saharan Africa [29]. As the African A- variant is not the most severe variant of G6PD deficiency, this warrants caution for extrapolating to regions where more severe variants are prevalent. For example, individuals with the Mediterranean G6PD-deficiency variant have much lower G6PD enzyme activity compared to the African A- variant and subsequently are more at risk of severe hemolytic events. It should also be acknowledged that the Tanzanian dataset we used for MDA simulations may differ from other sub-Saharan African populations. For example, the simulation data were collected from villages at different altitudes, and whilst this encompasses a range of malaria endemicities, population hemoglobin levels will differ from other areas. As with other similar chemotherapeutic interventions, the epidemiology of malaria and co-infections would need to be considered in designing and implementing an MDA with SLD-PQ. Furthermore, our simulations were based on the likely availability of lower strength tablets produced at good manufacturing practice standards in the near future.
These formulations are not currently available, and until then it will be more difficult to dose at the same precision as in our simulations. Lastly, it is important to emphasize that we have been cautious by using quite conservative definitions of anemia compared to other commonly used definitions, which further supports the safety of MDA with SLD-PQ in this population [47].

\section{Conclusions}

We predict a small drug concentration-dependent increase in hemolysis following primaquine administration, which disappears completely after 25 days. G6PD deficiency was associated with a 2.5 -fold larger reduction in hemoglobin levels. MDA with SLD-PQ is predicted to result in a small and transient relative increase in the prevalence of anemia. Children $<5$ years of age and women $\geq 15$ years of age were found to have a higher chance to have low pre-treatment hemoglobin. Individuals with low pre-treatment hemoglobin are at increased risk of severe anemia but this is also expected to be transitory. By exclusion from dosing of individuals with low pre-treatment hemoglobin, the incidence of severe anemia after SLD-PQ treatment could be limited. This study supports the feasibility of MDA with SLD-PQ in a subSaharan African setting where anemia may be common.

\section{Abbreviations}

SLD-PQ: Single low dose of primaquine; WHO: World Health Organization; G6PD: Glucose-6-phosphate dehydrogenase; CYP2D6: Cytochrome P450 D6; MDA: Mass drug administration; DP: dihydroartemisinin-piperaquine; AL: Artemether-lumefantrine; AS: Activity score; VPCs: Visual predictive checks.

\section{Supplementary Information}

The online version contains supplementary material available at https://doi. org/10.1186/s13071-021-05034-4.

Additional file 1: Table S1. Definition of anemia according the World Health Organization.

Additional file 2: Figure S1. Visual predictive checks for the final pharmacokinetic and pharmacodynamic models.

Additional file 3: Figure S2. Goodness-of-fit plots for the pharmacokinetic model.

Additional file 4: Figure S3. Goodness-of-fit plots for the pharmacodynamic model.

Additional file 5: Model code. NONMEM control stream of the pharmacokinetic/pharmacodynamic model.

Additional file 6: file 6: Table S2. Predicted median reduction in hemoglobin after 0.25 and $0.4 \mathrm{mg} / \mathrm{kg}$ primaquine stratified by CYP2D6 activity score group.

Additional file 7: Figure S4. Simulated hemoglobin distributions before and after treatment.

Additional file 8: Figure S5. Distribution of observed pre-treatment hemoglobin levels in the simulation dataset. 
Additional file 9: Table S3. Predicted prevalence of anemia and its severity after 0.25 and $0.4 \mathrm{mg} / \mathrm{kg}$ primaquine when heterozygous females are included in the G6PD-deficient group.

\section{Authors' contributions}

Conceived and designed the analysis: SWB, EMS, ABT, JO, UD, BPC, CD, TB, RH. Performed the analysis: SWB, EMS, RH. Wrote the manuscript: SWB, EMS, ABT, $J \mathrm{O}, \mathrm{UD}, \mathrm{BPC}, \mathrm{CD}, \mathrm{TB}, \mathrm{RH}$. All authors read and approved the final manuscript.

\section{Funding}

This work was supported in part by funding to CD and TB from the Bill \& Melinda Gates Foundation for the Primaquine supplement to AFIRM (OPP1034789). Sample collection and analysis in Tanzania were funded by Medical Research Council, UK, grant no. 9901439.

\section{Availability of data and materials}

The datasets used during the model development can be requested from the original authors through the Worldwide Antimalarial Resistance Network repository using their PubMed IDs (27010,542 and 26952094), https://app-live. wwarn.org/DatalnventoryExplorer/\#1.

Attribution of graphical abstract resources: Computer simulation icon designed by Srip from Flaticon-www.flaticon.com/authors/srip. Population icon icon designed by Smashicons from Flaticon - www.flaticon.com/autho rs/smashicons. Pill blister pack, map of Africa and erythrocytes icons designed by Servier Medical Art—smart.servier.com. Mosquito icon designed by Freepik: www.freepik.com.

\section{Declarations}

\section{Ethics approval and consent to participate}

No data were collected as part of this study, but ethical approval and consent to participate were provided as part of the original studies where the data we use originates from.

\section{Consent for publication}

Not applicable.

\section{Competing interests}

The authors have declared that no competing interests exist.

\section{Author details}

'Department of Pharmacy, Radboud Institute for Health Sciences, Radboud University Medical Center, Nijmegen, The Netherlands. ${ }^{2}$ Department of Pharmacy, Uppsala University, Uppsala, Sweden. ${ }^{3}$ National Center for Research and Training on Malaria (CNRFP), Ouagadougou, Burkina Faso. ${ }^{4}$ Department of International Public Health, Liverpool School of Tropical Medicine, Liverpool, UK. ${ }^{5}$ Medical Research Council Unit The Gambia at the London School of Hygiene \& Tropical Medicine, Faraja, The Gambia. ${ }^{6}$ London School of Hygiene \& Tropical Medicine, London, UK. ${ }^{7}$ Department of Medical Microbiology, Radboud University Medical Center, Nijmegen, The Netherlands.

\section{Received: 13 July 2021 Accepted: 23 September 2021}

Published online: 09 October 2021

\section{References}

1. World Health Organisation. World malaria report 2019. https://www. who.int/malaria/publications/world-malaria-report-2019/en/. Accessed 15 Sep 2021.

2. White NJ, Qiao LG, Qi G, Luzzatto L. Rationale for recommending a lower dose of primaquine as a Plasmodium falciparum gametocytocide in populations where G6PD deficiency is common. Malar J. 2012;11:418.

3. Rosenthal PJ. Has artemisinin resistance emerged in Africa? Lancet Infect Dis. 2021;21:1056-7.

4. Ndwiga L, Kimenyi KM, Wamae K, Osoti V, Akinyi M, Omedo I, et al. A review of the frequencies of Plasmodium falciparum Kelch 13 artemisinin resistance mutations in Africa. Int J Parasitol Drugs Drug Resist. 2021;16:155-61.

5. Beutler E. G6PD deficiency. Blood. 1994;84:3613-36.

6. Beutler E, Duparc S. Glucose-6-phosphate dehydrogenase deficiency and antimalarial drug development. Am J Trop Med Hyg. 2007;77:779-89.

7. Bowman ZS, Morrow JD, Jollow DJ, McMillan DC. Primaquine-induced hemolytic anemia: role of membrane lipid peroxidation and cytoskeletal protein alterations in the hemotoxicity of 5-hydroxyprimaquine. J Pharmacol Exp Ther. 2005;314:838-45.

8. Fletcher KA, Barton PF, Kelly JA. Studies on the mechanisms of oxidation in the erythrocyte by metabolites of primaquine. Biochem Pharmacol. 1988;37:2683-90

9. Pybus BS, Sousa JC, Jin X, Ferguson JA, Christian RE, Barnhart R, et al. CYP450 phenotyping and accurate mass identification of metabolites of the 8-aminoquinoline, anti-malarial drug primaquine. Malar J. 2012;11:259.

10. World Health Organisation. Mass drug administration for falciparum malaria: a practical field manual. https://www.who.int/publications/i/ item/9789241513104. Accessed 15 Sep 2021.

11. Goncalves BP, Tiono AB, Ouedraogo A, Guelbeogo WM, Bradley J, Nebie I, et al. Single low dose primaquine to reduce gametocyte carriage and Plasmodium falciparum transmission after artemether-lumefantrine in children with asymptomatic infection: a randomised, double-blind, placebo-controlled trial. BMC Med. 2016;14:40.

12. Bastiaens GJH, Tiono AB, Okebe J, Pett HE, Coulibaly SA, Goncalves BP, et al. Safety of single low-dose primaquine in glucose-6-phosphate dehydrogenase deficient falciparum-infected African males: two open-label, randomized, safety trials. PLoS ONE. 2018;13:e0190272.

13. Eziefula AC, Bousema T, Yeung S, Kamya M, Owaraganise A, Gabagaya $\mathrm{G}$, et al. Single dose primaquine for clearance of Plasmodium falciparum gametocytes in children with uncomplicated malaria in Uganda: a randomised, controlled, double-blind, dose-ranging trial. Lancet Infect Dis. 2014;14:130-9.

14. Watson J, Taylor WR, Menard D, Kheng S, White NJ. Modelling primaquine-induced haemolysis in G6PD deficiency. Elife. 2017;6:e23061.

15. Hayes DJ, Banda CG, Chipasula-Teleka A, Terlouw DJ. Modelling the therapeutic dose range of single low dose primaquine to reduce malaria transmission through age-based dosing. BMC Infect Dis. 2017;17:254.

16. Stepniewska K, Humphreys GS, Gonçalves BP, Craig E, Gosling R, Guerin PJ, et al. Efficacy of single dose primaquine with artemisinin combination therapy on P. falciparum gametocytes and transmission: a WWARN individual patient meta-analysis. J Infect Dis. 2020. https://doi.org/10.1093/ infdis/jiaa498.

17. Page-Sharp M, llett KF, Betuela I, Davis TME, Batty KT. Simultaneous determination of primaquine and carboxyprimaquine in plasma using solid phase extraction and LC-MS assay. J Chromatogr B Analyt Technol Biomed Life Sci. 2012;902:142-6.

18. Goncalves BP, Pett $H$, Tiono AB, Murry D, Sirima SB, Niemi M, et al. Age, weight, and CYP2D6 Genotype are major determinants of primaquine pharmacokinetics in African children. Antimicrob Agents Chemother. 2017;61:e02590-e2616.

19. Pang KS, Rowland M. Hepatic clearance of drugs. I. Theoretical considerations of a "well-stirred" model and a "parallel tube" model. Influence of hepatic blood flow, plasma and blood cell binding, and the hepatocellular enzymatic activity on hepatic drug clearance. J Pharmacokinet Biopharm. 1977;5:625-53.

20. Johnson TN, Tucker GT, Tanner MS, Rostami-Hodjegan A. Changes in liver volume from birth to adulthood: a meta-analysis. Liver Transpl. 2005;11:1481-93.

21. Anderson BJ, Holford NH. Mechanism-based concepts of size and maturity in pharmacokinetics. Annu Rev Pharmacol Toxicol. 2008;48:303-32.

22. Beal SL. Ways to fit a PK model with some data below the quantification limit. J Pharmacokinet Pharmacodyn. 2001;28:481-504.

23. Gaedigk A, Simon SD, Pearce RE, Bradford LD, Kennedy MJ, Leeder JS. The CYP2D6 activity score: translating genotype information into a qualitative measure of phenotype. Clin Pharmacol Ther. 2008;83:234-42.

24. Gaedigk A, Dinh JC, Jeong H, Prasad B, Leeder JS. Ten years' experience with the CYP2D6 activity score: a perspective on future investigations to improve clinical predictions for precision therapeutics. J Pers Med. 2018;8:15. 
25. Lledo-Garcia R, Kalicki RM, Uehlinger DE, Karlsson MO. Modeling of red blood cell life-spans in hematologically normal populations. J Pharmacokinet Pharmacodyn. 2012;39:453-62.

26. Drakeley CJ, Carneiro I, Reyburn H, Malima R, Lusingu JP, Cox J, et al. Altitude-dependent and -independent variations in Plasmodium falciparum prevalence in northeastern Tanzania. J Infect Dis. 2005;191:1589-98.

27. Sepúlveda N, Manjurano A, Campino SG, Lemnge M, Lusingu J, Olomi R, et al. Malaria host candidate genes validated by association with current, recent, and historical measures of transmission intensity. J Infect Dis. 2017;216:45-54

28. Pett H, Bradley J, Okebe J, Dicko A, Tiono AB, Goncalves BP, et al. CYP2D6 polymorphisms and the safety and gametocytocidal activity of singledose primaquine for Plasmodium falciparum. Antimicrob Agents Chemother. 2019;63:e00538-e619.

29. Howes RE, Piel FB, Patil AP, Nyangiri OA, Gething PW, Dewi M, et al. G6PD deficiency prevalence and estimates of affected populations in malaria endemic countries: a geostatistical model-based map. PLoS Med. 2012;9:e1001339.

30. World Health Organisation. Haemoglobin concentrations for the diagnosis of anaemia and assessment of severity; 2011. https://www.who.int/ vmnis/indicators/haemoglobin.pdf. Accessed 15 Sep 2021.

31. R Core Team. R: A language and environment for statistical computing. Vienna, Austria: R Foundation for Statistical Computing; 2016. https:// www.R-project.org/. Accessed 15 Sep 2021.

32. Beal S, Sheiner LB, Boeckmann A, Bauer RJ. NONMEM user's guides (1989-2009). Ellicott City: Icon Development Solutions; 2009.

33. Keizer RJ, Karlsson MO, Hooker A. Modeling and simulation workbench for NONMEM: tutorial on Pirana, PsN, and Xpose. CPT Pharmacometr Syst Pharmacol. 2013;2:e50.

34. Bergstrand M, Hooker AC, Wallin JE, Karlsson MO. Prediction-corrected visual predictive checks for diagnosing nonlinear mixed-effects models. AAPS J. 2011;13:143-51.

35. Bauer RJ. NONMEM tutorial part II: estimation methods and advanced examples. CPT Pharmacometr Syst Pharmacol. 2019;8:538-56.

36. Franco RS. Measurement of red cell lifespan and aging. Transfus Med Hemother. 2012;39:302-7.

37. Looareesuwan S, Davis TM, Pukrittayakamee S, Supanaranond W, Desakorn V, Silamut K, et al. Erythrocyte survival in severe falciparum malaria. Acta Trop. 1991;48:263-70.
38. Karafin MS, Francis RO. Impact of G6PD status on red cell storage and transfusion outcomes. Blood Transfus. 2019;17:289-95.

39. Eziefula AC, Pett H, Grignard L, Opus S, Kiggundu M, Kamya MR, et al. Glucose-6-phosphate dehydrogenase status and risk of hemolysis in Plasmodium falciparum-infected African children receiving single-dose primaquine. Antimicrob Agents Chemother. 2014;58:4971-3.

40. Kheng S, Muth S, Taylor WR, Tops N, Kosal K, Sothea K, et al. Tolerability and safety of weekly primaquine against relapse of Plasmodium vivax in Cambodians with glucose-6-phosphate dehydrogenase deficiency. BMC Med. 2015;13:203

41. Landier J, Kajeechiwa L, Thwin MM, Parker DM, Chaumeau V, Wiladphaingern J, et al. Safety and effectiveness of mass drug administration to accelerate elimination of artemisinin-resistant falciparum malaria: a pilot trial in four villages of Eastern Myanmar. Wellcome Open Res. 2017;2:81.

42. von Seidlein L, Peto TJ, Landier J, Nguyen TN, Tripura R, Phommasone K, et al. The impact of targeted malaria elimination with mass drug administrations on falciparum malaria in Southeast Asia: a cluster randomised trial. PLoS Med. 2019;16:e1002745.

43. LaRue N, Kahn M, Murray M, Leader BT, Bansil P, McGray S, et al. Comparison of quantitative and qualitative tests for glucose-6-phosphate dehydrogenase deficiency. Am J Trop Med Hyg. 2014;91:854-61.

44. Bancone G, Kalnoky M, Chu CS, Chowwiwat N, Kahn M, Malleret B, et al. The G6PD flow-cytometric assay is a reliable tool for diagnosis of G6PD deficiency in women and anaemic subjects. Sci Rep. 2017;7:9822.

45. Stevens JC, Marsh SA, Zaya MJ, Regina KJ, Divakaran K, Le M, et al. Developmental changes in human liver CYP2D6 expression. Drug Metab Dispos. 2008;36:1587-93.

46. Setyadi A, Arguni E, Kenangalem E, Hasanuddin A, Lampah DA, Thriemer $K$, et al. Safety of primaquine in infants with Plasmodium vivax malaria in Papua. Indonesia Malar J. 2019;18:111.

47. White NJ. Anaemia and malaria. Malar J. 2018;17:371.

\section{Publisher's Note}

Springer Nature remains neutral with regard to jurisdictional claims in published maps and institutional affiliations.
Ready to submit your research? Choose BMC and benefit from:

- fast, convenient online submission

- thorough peer review by experienced researchers in your field

- rapid publication on acceptance

- support for research data, including large and complex data types

- gold Open Access which fosters wider collaboration and increased citations

- maximum visibility for your research: over $100 \mathrm{M}$ website views per year

At BMC, research is always in progress.

Learn more biomedcentral.com/submissions 